\title{
Detection and Frequency of Enterotoxin (cpa, cpe) Genes of Clostridium perfringens Isolated from Dehydrated Vegetables by PCR
}

\author{
Sedighe Ghourchian1 $^{1(D)}$, Masoumeh Douraghi',3 ${ }^{2}$, Akram Baghani2 ${ }^{\text {(D) }}$, \\ Mohammad Mehdi Soltan Dallal ${ }^{1,2,3 *}$ id
}

1. Division of Food Microbiology, Dept. of Pathobiology, School of Public Health, Tehran University of Medical Sciences, Tehran, Iran

2. Division of Medical Bacteriology, Dept. of Pathobiology, School of Public Health, Tehran University of Medical Sciences, Tehran, Iran

3. Food Microbiology Research Center, Tehran University of Medical Sciences, Tehran, Iran

\begin{tabular}{|c|c|}
\hline Article Info & ABSTRACT \\
\hline /jambs.29.133.63 & \multirow{2}{*}{$\begin{array}{l}\text { Background \& Objective: Clostridium perfringens is an anaerobic bacterium, } \\
\text { commonly present in retail foods. Its enterotoxin-producing ability, short generation } \\
\text { time, ability to grow at elevated temperatures, and spore-forming ability allow } C \text {. } \\
\text { perfringens to survive in food-processing temperatures, and cause foodborne illness. } \\
\text { The aim of study was to screen dehydrated vegetables contaminated with Clostridium } \\
\text { perfringens enterotoxin }(C P E) \text { and } C \text {. perfringens alpha-toxin }(C P A) \text {. }\end{array}$} \\
\hline $\begin{array}{l}\text { Received: 2020/03/25; } \\
\text { Accepted: } 2020 / 07 / 16 \\
\text { Published Online: } 04 \text { Dec } 2020\end{array}$ & \\
\hline Use your device to scan and read the & $\begin{array}{l}\text { Materials \& Methods: This descriptive-analytical study was carried out on } 140 \\
\text { samples ( } 70 \text { unpacked and } 70 \text { packed). The samples included dehydrated vegetables } \\
\text { collected from different areas of Tehran, Iran. Samples were inoculated on peptone } \\
\text { and sulfite polymyxin sulfadiazine (SPS) agar for enrichment. The enrichment culture } \\
\text { was then incubated on anaerobic condition for } 48 \text { hours. The black colonies were } \\
\text { selected for identification test and polymerase chain reaction (PCR). The bacterial } \\
\text { colonies were identified by biochemical tests, and duplex PCR was performed for } C P E \\
\text { and } C P A \text { genes. }\end{array}$ \\
\hline \multirow{3}{*}{$\begin{array}{l}\text { Corresponding Information: } \\
\text { Mohammad Mehdi Soltan Dallal, } \\
\text { Food Microbiology Research Center/ } \\
\text { Division of Food Microbiology, } \\
\text { Department of Pathobiology, School of } \\
\text { Public Health, Tehran University of } \\
\text { Medical Sciences, Tehran, Iran. } \\
\text { E-Mail: } \\
\text { msoltandallal@gmail.com }\end{array}$} & $\begin{array}{l}\text { Results: In general, } 13 \text { samples }(9.3 \%) \text { were identified as contaminated with } C \text {. } \\
\text { perfringens using phenotypic methods; all of the isolates were also positive for } C P A \text {, } \\
\text { but negative for } C P E \text { gene. The contamination rate for packed and unpacked } \\
\text { vegetables was } 12.8 \% \text { and } 5.7 \% \text {, respectively. }\end{array}$ \\
\hline & $\begin{array}{l}\text { Conclusion: Our findings showed that contamination of packed samples was higher } \\
\text { than unpacked ones, which might be due to drying as well as packaging process. } \\
\text { We found that these isolates were negative for enterotoxin. }\end{array}$ \\
\hline & Keywords: Clostridium perfringens, Dehydrated vegetables, Enterotoxin \\
\hline $\begin{array}{l}\text { opyright } 1 \text { 2 } 2021 \text {, This is } \\
\text { opy and redistribution of }\end{array}$ & $\begin{array}{l}\text { ess article distributed under the terms of the Creative Con } \\
\text { oncommercial usages with proper citation. }\end{array}$ \\
\hline
\end{tabular}

\section{Introduction}

Clostridium perfringens ranks among the most widespread bacteria, with an ubiquitous environmental distribution in soil, sewage, food, feces, and the normal intestinal flora of humans and animals $(1,2)$. According to the Center for Disease Control and Prevention (CDC) estimation, more than one million people are infected by $C$. perfringens each year (3). Food poisoning can be caused by $C$. perfringens enterotoxin (CPE) produced by $C$. perfringens spores in the small intestine, which can germinate in foods such as meat and poultry. Main symptoms of the disease are nausea, abdominal pain, and diarrhea. The disease is usually mild and self-limiting in healthy individuals, with symptoms resolving within 24 hours $(4,5)$. The $C P E$ is encoded by its gene located on the chromosome or plasmid of the bacterium (6-8). Expression of the $C P E$ is an important determinant of $C$. perfringens causing food poisoning (9). Available diagnostic tests for the toxin detection are immunoenzymatic assays including latex agglutination, immunodiffusion, immunoelectrophoresis, ELISA, and Western blot. All these tests depend on high quantity of the enterotoxin in samples. Some strains may carry a silent $C P E$ gene, resulting in missed identification of toxigenic strains. One of the reliable and useful methods for the detection of $C$. perfringens toxins is polymerase chain reaction (PCR). This method does not depend on enterotoxin concentration (10). Many of $C$. perfringens food poisoning events occur due to the consumption of 
contaminated meat and poultry products (11). Detection of toxigenic $C$. perfringens is important because spore forming bacteria are Stable in the environment. The dehydrated vegetables are routinely used in Iran in various foods, including main dishes and herbal medicines. The aim of this study was to isolate and identify $C$. perfringens in dehydrated vegetables in Iran.

\section{Materials and Methods}

\section{Sampling}

A total of 140 samples of dehydrated green leafy vegetables, including dill, parsley, coriander, tarragon, mint, and mixed vegetables (crumb and soup) were collected from different areas of Tehran, Iran. Samples were collected as unpacked dehydrated vegetables $(n=70)$ and packed $(n=70)$. The study was approved by the Ethics Committee of Tehran University of Medical Sciences (code=IR.TUMS.SPH.REC.1394.775).

\section{Culture and Isolation}

To evaluate the samples, $10 \mathrm{~g}$ of dehydrated vegetables was diluted in $90 \mathrm{~mL}$ of sterile $0.1 \%$ peptone water, then $10 \mathrm{~mL}$ of this suspension was added to 10 $\mathrm{mL}$ of thioglycollate medium. Two thioglycollate tubes were prepared from each sample, one tube was incubated at $75^{\circ} \mathrm{C}$ for $30 \mathrm{~min}$ for the detection of $C$. perfringens spores and the second tube was incubated at $37^{\circ} \mathrm{C}$ in an anaerobic jar with Anaerocult A for $48 \mathrm{~h}$. After enrichment step, the supernatant was discarded, and two drops of the pellets were streaked on sulfite polymyxin sulfadiazine (SPS) agar plates and incubated at $37^{\circ} \mathrm{C}$ for $24-48 \mathrm{~h}$ in an anaerobic jar. Black colonies on SPS agar were subjected to Gram staining and biochemical tests.

\section{Biochemical Tests}

Black colonies were assessed for nitrate reduction, gelatinase, production of double zone, motility test, lecithinase production in egg yolk agar, and acid production by lactose and glucose fermentation. The isolates confirmed as $C$. perfringens were stored at $20^{\circ} \mathrm{C}$.

\section{PCR}

For genomic DNA extraction, 5-6 colonies grown on SPS agar were inoculated in $200 \mu \mathrm{l}$ of sterile double distilled water and boiled at $100^{\circ} \mathrm{C}$ for $5-10 \mathrm{~min}$. Following the centrifugation at $12,000 \mathrm{~g}$ for $3 \mathrm{~min}$, the supernatant was used as the template DNA for PCR assay $(12,13)$. The specific primers were used to amplify 324 and 233 base pair (bp) of C. perfringens alpha-toxin $(C P A)$ and $C P E$ genes, respectively (Table1). Reference strain of $C$. perfringens strain CIP 106157 was used as a positive control for detection of $C P A$ and $C P E$ genes. The PCR was performed in a total volume of $20 \mu \mathrm{L}$ containing $10 \mu \mathrm{L}$ of master mix (Pishgam, Iran), $10 \mathrm{ng}$ of DNA, $8.5 \mu \mathrm{L}$ of $\mathrm{H}_{2} \mathrm{O}$, and $0.25 \mathrm{mM}$ of each primer (Bioneer, Seoul, South Korea). Thermo cycler (Peqlab, Germany) was set with the following conditions: initial denaturation at $95^{\circ} \mathrm{C}$ for $5 \mathrm{~min}$ and 30 cycles including denaturation at $94^{\circ} \mathrm{C}$ for $1 \mathrm{~min}$, annealing at $55^{\circ} \mathrm{C}$ for 2 min, extension at $72^{\circ} \mathrm{C}$ for $3 \mathrm{~min}$, and final extension at $72^{\circ} \mathrm{C}$ for $4 \mathrm{~min}$ (14). Electrophoresis was performed in $1 \%$ agarose gels (Invitrogen, USA) and gel was stained with $0.5 \mu \mathrm{g} \mathrm{ml}^{-1}$ ethidium bromide (Sigma, USA).

\section{Nucleotide Accession Number}

The partial sequence of $C P A$ gene was deposited in GenBank under the accession number of KU166870.

Table 1. Specific primer sequences targeting cpa and cpe

\begin{tabular}{cccc} 
Sene & Sequence $\left(5^{\prime}-3^{\prime}\right)$ & Amplicon size (bp) & Reference \\
Cpa & GCTAATGTTACTGCCGTTGA & 324 & $(9)$ \\
CC TCTGATACATCGTGTAA & GGAGATGGTTGGATATAGG & 3233 & $(9)$ \\
\hline
\end{tabular}

\section{Results}

Out of 140 samples, $13(9.3 \%)$ were identified as contaminated with $C$. perfringens. Among the contaminated samples, $9(12.8 \%)$ and $4(5.7 \%)$ samples were from packed and unpacked samples, respectively. Based on dried vegetables breeds showed no contaminations in soap vegetables, while $1(0.7 \%)$ parsley, $2(1.4 \%)$ coriander, 2 (1.4\%) mint, 2 (1.4\%) tarragon, 3 (2.2\%) dill, and $3(2.1 \%)$ vegetable crumble samples were contaminated with $C$. perfringens. Using duplex PCR, all isolates were positive for $C P A$ gene while all were negative for $C P E$ gene (Figure 1). This finding indicated that the rate of $C$. perfringens was $12.8 \%$ on the packed dehydrated vegetables and $5.7 \%$ on unpacked vegetables. 


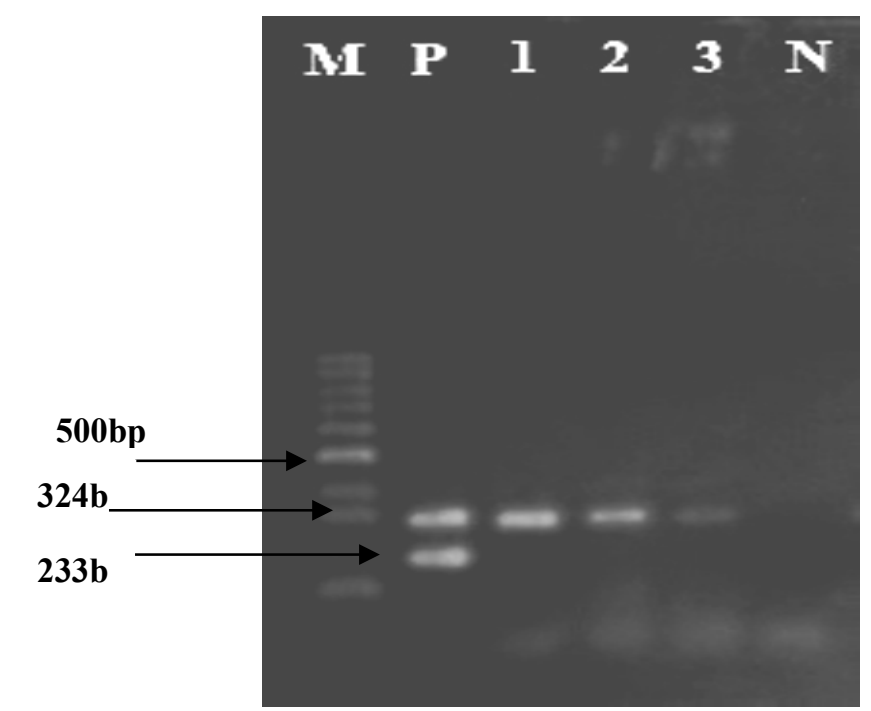

Figure1. Duplex PCR for cpa and cpe genes. M: marker 100bp, P: CIP106157 positive control for cpa and cpe genes. N: negative control. Line

\section{Discussion}

Our results showed that there was no relationship between the positive rate of $C$. perfringens and brand or breed of the vegetables. Although there are many studies on typing and toxin detection of C. perfringens, none of them has investigated the contamination of dried vegetables so far. Dried vegetables are usually used as cooked or undercooked; thus, consumption of these products may result in food illness. In addition, if the products are contaminated with spores, the stability of spore to heat is another problem (15).

Despite the low frequency of $C P E$ positive and $C$. perfringens in foods especially in meat, poultry, and dried vegetables, these products can be sources of toxins. Various reports showed that the rate of $C$. perfringens-associated food poisoning varies around the world $(11,16,17)$. Unfortunately, there is no comprehensive data showing the frequency of $C$. perfringens in food poisoning in Iran. This could be due to various reasons including difficulty in registration of patient data or short period of symptoms $(24 \mathrm{~h})$. In this study, we determined that $9.3 \%$ of dehydrated vegetables were contaminated with $C$. perfringens. This contamination might be due to the presence of spores in dehydrated samples. The spores are resistant to desiccation, heating, and other conditions. In 2009, Sagoo et al. reported that $C$. perfringens contamination in dried vegetables and spices is $0.4 \%$. In some other studies conducted in the UK $(1975,1985,1986)$, the isolation rate of $C$. perfringens isolation from dried vegetables was 0 to $7.6 \%$ (15).

The frequency of $C$. perfringens isolated from packed vegetables was more than unpacked ones. This finding may be related to inappropriate processing during packaging or lack of hygiene consideration in factory, transportation, and packaging. The isolates were investigated for $C P A$ and $C P E$ genes. Duplex PCR was applied for 13 confirmed isolates, in which all samples were positive for $C P A$ gene and negative for $C P E$ gene. As far as the researchers investigated, no study has been carried out on dehydrated vegetables in Iran yet. But some studies have been carried out in Iran on isolation of $C$. perfringens from poultry meats. Poursoltani et al. (in 2014) detected six isolates from 180 packed poultry samples. They used multiplex PCR for $C$. perfringens subtyping and single PCR for net $B$ and tpel genes in poultry with necrotic enteritis symptoms (18). In Iran, Zandi et al. (in 2014) showed that $100 \%$ ostrich dung samples were positive for $C P A$ gene. The multiplex PCR method was used that have not been reported in Iran (19). The difference in frequency of contamination may be due to different contamination sources. Erol et al. (2008) used multiplex PCR on ostrich meat, and showed that $12.2 \%$ (22/180) isolates were positive for CPA gene but negative for $C P E$ gene (12).

\section{Conclusion}

Our results showed that $13(9.3 \%)$ samples were contaminated with $C$. perfringens. However, the bacteria were negative for $C P E$. The higher contamination rates in packed vegetables compared to unpacked ones might indicate the lack of suitable hygienic considerations on drying and packaging processes.

\section{Acknowledgments}

This paper is part of a research project approved by the Food Microbiology Research Center, Tehran University of Medical Sciences and Health Services Contract No. 28439. The authors would like to thank 
Dr. Zahraei Salehi from Tehran Veterinary University for providing us a $\mathrm{C}$. perfringens strain as control.

\section{Ethical considerations}

Ethical issues (Including plagiarism, informed consent, misconduct, data fabrication and/or falsification, double publication and/or submission, redundancy, etc.) have been completely observed by the authors.

\section{Funding and support}

This research resulted from an independent research without receiving any financial support.

\section{Conflict of Interest}

Authors declared no conflict of interest.

\section{References}

1. Lindström M, Heikinheimo A, Lahti P, et al.Novel insights into the epidemiology of Clostridium perfringens type A food poisoning. Food microbiol.2011;28(2):192-198.

\section{[DOI:10.1016/j.fm.2010.03.020]}

2. ScallanE, Hoekstra RM, Angulo FJ,et al. ( 2011). Foodborne illness acquired in the United Statesmajor pathogens. Emerg Infect Dis,17(1).7-15. [DOI:10.3201/eid1701.P11101]

3. Grass JE, Gould LH, Mahon BE. Epidemiology of foodborne disease outbreaks caused by Clostridium perfringens, United States, 1998-2010. Foodborne PathogDis.2013;10(2):131-36. [DOI:10.1089/fpd.2012.1316]

4. Bos J, Smithee L, McClane B, et al.Fatal necrotizing colitis following a foodborne outbreak of enterotoxigenic Clostridium perfringens type A infection. Clin Infect Diseas.2005; 40(10):78-83. [DOI:10.1086/429829]

5. SchneiderK.R, Goodrich-Schneider R, Hubbard MA, Richardson S.(2017). Preventing foodborne illness associated with Clostridium perfringens. FSHN035,1-6.

6. Hassan KA, Elbourne LD, Tetu SG, et al. Genomic analyses of Clostridium perfringens isolates from five toxinotypes. Res Microbiol.2015;166(4):255263. [DOI:10.1016/i.resmic.2014.10.003]

7. LahtiP, Heikinheimo A, Johansson $\mathrm{T}$, et al. Clostridium perfringens type A strains carrying a plasmid-borne enterotoxin gene (genotype IS1151cpe or IS1470-like-cpe) as a common cause of food poisoning. J Clin Microbiol.2008; 46(1):371-373. [DOI:10.1128/JCM.01650-07]

8. Ma M, Li J , McClane BA. Genotypic and phenotypic characterization of Clostridium perfringens isolates from Darmbrand cases in post-
World War II Germany. Infect immun.2012; 80(12):4354-4363. [DOI:10.1128/IAI.00818-12]

9. Miyamoto K, Li J , McClane BA. Enterotoxigenic Clostridium perfringens: detection and identification. Microbes Environ. 2012;27(4):343349. [DOI:10.1264/jsme2.ME12002]

10. Abdelrahim AM, Radomski N, Delannoy S, et al. Large-scale genomic analyses and toxinotyping of Clostridium perfringens implicated in foodborne outbreaks in France. Front Microbiol. 2019; 10:777. [DOI:10.3389/fmicb.2019.00777]

11. Lindström M, Heikinheimo A, Lahti P, Korkeala H. Novel insights into the epidemiology of Clostridium perfringens type A food poisoning. Food Microbiol. 2011;28(2):192-8. [DOI:10.1016/j.fm.2010.03.020]

12. Erol I, Goncuoglu M, Ayaz N, et al. Molecular typing of Clostridium perfringens isolated from turkey meat by multiplex PCR. Lett Appl Microbiol.2008, 47(1): 31-34. [DOI:10.1111/j.1472-765X.2008.02379.x]

13. Ossiprandi MC, Zerbini L. Molecular evaluation of the enterotoxigenicity of Clostridium difficile and Clostridium perfringens swine isolates by PCR assays. Adv Microbiol,2013; 3: 154-59. [DOI:10.4236/aim.2013.32024]

14. Miki Y, Miyamoto K, Kaneko-Hirano I,et al. Prevalence and characterization of enterotoxin gene-carrying Clostridium perfringens isolates from retail meat products in Japan. Appl Environ Microbiol. [DOI:10.1128/AEM.00783-08]

15. Sagoo S k, Little CL, Greenwood M, et al. Assessment of the microbiological safety of dried spices and herbs from production and retail premises in the United Kingdom. Food microbiol.2009; 26(1) 39-43. [DOI:10.1016/j.fm.2008.07.005]

16. Miyamoto K, Li J, McClane BA. Enterotoxigenic Clostridium perfringens: detection and identification. Microbes Environ. 2012;27(4):3439. [DOI:10.1264/jsme2.ME12002]

17. Kaneko I, Miyamoto K, Mimura K, et al.Detection of enterotoxigenic Clostridium perfringens in meat samples by using molecular methods. Appl Environ Microbiol.2011; 77(21):7526-32. [DOI:10.1128/AEM.06216-11]

18. Poursoltani M, Mohsenzadeh M, Razmyar J. Toxinotyping of Clostridium perfringens strains isolated from packed chicken portions. Iranian $\mathrm{J}$ Medl Microbiol.2014; 8(1):9-17.

19. Zandi E, Mohammadabadi M, Ezzatkhah M, et al. Typing of toxigenic isolates of Clostridium perfringensby multiplex PCR in ostrich. Iranian J Appl Anim Sci.2014; 4(4):795-801. 


\section{How to Cite This Article:}

Ghourchian S, Douraghi M, Baghani A, Soltan Dallal M M. Detection and Frequency of Enterotoxin (cpa,cpe) Genes of Clostridium perfringens Isolated from Dehydrated Vegetables by PCR. J Adv Med Biomed Res. 2021; 29 (133):63-67

\section{Download citation:}

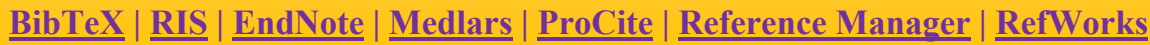

\section{Send citation to:}

(37. Mendeley 2 Zotero 目RefWorks $\underline{\text { RefWorks }}$ 